\title{
RELATIONSHIP OF CANE VARIETIES TO DISEASES
}

Menvilus T. Cook, Plant Pathologist, Insular Experiment Station, Río Picdras, P. R.

It is very generally reeognized that some varieties of plants are much more resistant to certain cliseases than other's. This is very readily observed in both wild and cultivated plants. Even the most casual observer cannot fail to note that diseases do not spread uniformly through a growth of wild plants or over a field of cultivated plants. This is because some plants are more resistant than others. Susceptibility to disease may account for the complete extermination of some species and varieties of wild plants in the past. It certainly does account for the abandomment of some varieties of cultivated plants within very recent time.

The fact that some plants are more resistant to certain diseassis than others has leen utilized by the growers of plants for many years; in fact, this practice is so old that it is impossible to tell jast when man first began to select plants that were resistant to discase. Within recent years, many diseases of plants have been brought under control by the selection of resistant strains and varieties and this method is now very generally recognized as one of the most important in our fight against the many diseases of our erops.

The sugar-cane growers of Porto Rico have long ago learned that the selection of resistant varieties is a most important method of fighting some of our enemies. The growing of the recognized varieties of twenty-five years ago, have been greatly reduced, because of their susceptibility to mosaic and new and more resistant varieties have come into use. A few years ago, the gummosis dusease became a threatening factor in Porto Rico, but is now of comparatively little importance because our growers have learned that it can be climinated by the growing of resistant varieties (See Matz, J., Gumming Disease of Sugar Cane", Journal of the Department of Agriculture, 6:5-21, July, 1922).

But our growers have also learned that resistance to dissease is cmly one of many variations of sugar cane. Varieties differ greatly in character of growth, amount of tomnage, fiber, sucrose, and cther factors which are quite important. This is true, not only in Porto Rico, but also in other cane-growing regions of the world 
and is probably the most important line on which our specialists are working for the advancement of the sugar-cane industry. The result is that the development of sugar-cane varieties is receiving more attention at present than at any other time in the history of the sugar industry and new varieties are being developed in great numbers.

With these facts before us, let us inquire a little more closely into the question of varieties and their relation to the future of the cane-growing industry. It has been long recognized that all plants are subject to variation; in fact, it is often said that no two plants are exactly alike. The resemblances may be so close that it is practically impossible to detect the difference, but the differences are there: and it is this tendency to vary that has given rise to the enormous number of varieties of eultivated plants. In fact, some of the greatest advances in agriculture have been made by workers who were able to recognize and preserve valuable varieties. This has been practiced for centuries more or less blindly by men who did not understand natural laws of variation which have been demonstrated in recent years.

Varieties may arise in several ways, but the three most common are:

1. A gradual variation in which it is mecessary to select the most desirable plants through a number of generations. In this manner the desired plant may eventually be secured.

2. Very promounced and stable rariations may appear within a single generation. These variations are known as "Mutants" and may be good or bad. These variations must be studied by well trained workers and tested from many angles in order to determine their relative values.

3. The careful breeding of plants by cross-pollination and procluction of seedling from which selections must be made by competent indges. This has become a very general practice in many of the canegrowing regions of the world and has given rise to a large number Git seedlings.

The selection of desirable varieties by one who understands what i* wanted may at first appear to be a simple process, but plants possess enormous numbers of characters, some desirable, some un. desirable, some prominent and easily recognized, others hidden and erasive. Furthermore, this enormous number of eharacters are subject to an endless number of groupings. It will be readily seen that these factors give rise to a great number of complications. But this is not all: a variety may behave quite differently in different 
parts of the world or under different enviroumental conditions in contiguous territory.

The growing of new varieties has now reached proportions unthought of a quarter of a century ago and new varieties come and go with such rapidity and in such great numbers as to be almost hewildering.

It is the purpose of this paper to consides: this subject of new varieties from one angle only-that of plant disease. Of course, a new variety that does not grow well, give good tomnage, good sucrose content, and possess other qualities that are desirables from the standpoint of sugar production, will be eliminated from consideration.

Many of the breeders of sugar cane are thinking more of tonnage and sucrose content than of other factors. But a cane that possesses these good qualities may also possess bad qualities such as susceptibility to some of our well-known diseases. Even a seedling from parents that are resistant to a disease may prove to be very susceptible to that same disease.

But there are two other factors which must not be overlooked. (1) An insignificant disease may find a new variety so farorable for its growth, that it will suddenly become a disease of major importance. (2) A disease of grass may find the new variety of cane to its liking and develop into a serious problem.

Let us take a few examples:

(1) Cane mosaic must have existed previons to the first report from Java in 1890 . It is easy to say that it spread from Java throughcut the greater part of the cane-growing world, but that it is not easily proven. However, no one who has studied the subject will fail to understand that it has a very definite relationship to other varieties. This is well know to our Porto Rican growers and the use of resistant varieties has been and probalyly will continue to be one of the most important methods of fighting this disease.

(2) The vascular disease or dry top rot (Plasmodiophora vascularkm) which has been found only in Porto Rico. It is especially severe on D-109, when grown in low, rather wet land, but it also attacks several other varieties. Where did it come from? How long has if been an enemy to cane? It appears that the best method of combating this disease may be in the use of a resistant variety.

(3) The "eye spot" 1 is a very old and very widely distributed disease. It may have been in Porto Rico for centuries, but was

1 Sometimes called the Manati disease. 
never considered an important factor until 1923. It is now looked upon as one of our most important diseases. It has no doubt suddenly become serious because of the coming of new varieties of cane which are susceptible. In Hawaii this disease is most severe on $\mathrm{H}-109$, but in Porto Rico we have a number of varieties that are more susceptible such as D-109 and $\mathrm{FC}-306$. This is one of our important problems and it appears at this time that the selection of varieties and place of planting will be the two most important factors in controlling this disease.

(4) Gummosis was first found in Porto Rico in 1920, although . it was reported from Australia a quarter of a century before that date. It may not be possible to determine where it originally came from or how long it had been in Porto Rico previous to its discovery, but it has been demonstrated that it can be controlled by the use of resistant varieties.

These four important diseases (mosaic, dry top rot, eye-spot, and gummosis) are well known to this audience. They have all, with the exception of the "eye spot", been discovered in Porto Rico within the past ten year's, although they may have been here a much longer time. In fact, the "eye spot" may have been here almost from the beginning of the sugar industry. Their history in Porto Rico is a most excellent proof of the importance of the selection of resistant varieties in the growing of sugar cane.

The records show a dozen or more minor diseases of sugar cane in Porto Rico, any one of which may become of importance at any time provided it finds a suitable host variety. Minor diseases which suddenly become important are frequently looked upon as "new" by those who are unfamiliar with plant diseases, but if we could only learn their full history, we would find that some of them were formerly minor diseases while others may have come from related uneultivated plants.

But the selection of varieties of high tonnage, high sucrose content, and high resistance to disease must bring other factors into consideration, the most important of which are relationship to soil and climate. This is well illustrated in the case of the "eye spot" which is most severe in regions and during periods of high rainfall. Although this disease was severe in 1923, it did not attract much attention in 1924, but was very abundant in 1925 . It is now looked unon by many of our growers as a disease of major importance and is one of our major problems at the Insular Experiment Station.

Therefore, it appears that the development of new varieties will 
very probably bring into prominence certain diseases which are of minor importance at this time and that our problems will become more and more complex. However, this must not be interpreted as an argument against the development of new varieties. The derelopment of new varieties is the key to progress in the sugar industry in Porto Rico and in other parts of the world. But we must recognize that our troubles are not ended with the mastery of mosaic.

New and more complex problems will arise from time to time with the finding of varieties of high tonnage and high sugar content. Tivery advance in the development of improved varieties will introduce new problems of diseases and some of these problems may be far more complex than those that are before us. 